\title{
Railway Disaster Prevention and Snow Survey Design Optimization Technology
}

\author{
Yong Qin ${ }^{1,2,3}$ Lei Zhu ${ }^{1,2, *}$ Zhenyu Zhang ${ }^{1,2}{\text { Linlin } \mathrm{Kou}^{1,2} \text { and Xiaoqing Cheng }}^{1,2}$
}

\author{
${ }^{I}$ State Key Laboratory of Rail Traffic Control and Safety, Beijing Jiaotong University, Beijing, China; ${ }^{2}$ School of Traffic \\ and Transportation, Beijing Jiaotong University, Beijing, China; ${ }^{3}$ Beijing Research Center of Urban Traffic Information \\ Sensing and Service Technologies, Beijing Jiaotong University, China
}

\begin{abstract}
Snow disasters cause immeasurable losses to human society each year, threatening people's lives and properties and therefore attaching much importance to the measurement of snow cover. Snowfall, however, is one of the most difficult to be measured among meteorological elements, especially on the railways. To solve this problem, the real-time monitoring of snow along the railway can be helpful. This can effectively avoid railway accidents caused by snowstorms, improving transport safety and efficiency as well as providing a quantitative reference for the safe operation of the railway. In this paper, a snow disaster prevention system is designed to measure the snow depth and issue the early warning. Also this paper achieves measurement by the integration of laser and video, where laser distance sensors detect snow depth and image sensors capture videos to find out whether the track is covered with snow and to obtain snow depth with the help of photographing rulers.
\end{abstract}

Keywords: Laser, measurement of snow depth, railway disaster prevention, video.

\section{INTRODUCTION}

With the rapid development of China's railway system, natural disasters (e.g. wind, rain, snow and earthquakes) and foreign body invasion become hidden dangers to safe operations, and therefore it is especially important to establish disaster prevention systems. As the key equipment of railway disaster prevention system, snow measurement device can provide the necessary security for the high-speed rail to run in heavy snow area.

According to Table 1, snow hazards can be analyzed; disaster prevention measure snow system should monitor snow depth, snowfall, snow intensity, the physical properties of snow measurement, and snow forecast snow information in real time. According to pre-set warning threshold, the system should timely alarm and propose traffic control plans to ensure traffic safety features. This article focuses on realtime monitoring of snow depth in-depth analysis.

This paper serves the purpose of measuring snow depth with the combination of laser and video, according to external climatic conditions and railway work environment formulation, in order to achieve the timeliness and accuracy of the measurement and to lay the foundation for further data processing and analysis.

The research base values of Chinese high-speed rail disaster protection is some few, by contrast, Japanese and European high-speed rail technology is relatively mature. Konosuke and Nisllimura used a box-type snow collector to

*Address correspondence to this author at the School of Beijing Jiaotong University, Beijing, 100044, P.R. China; Tel: +8613121536433;

E-mail: z1710720656@163.com research which is invented by Schmidt. They studied the relationship among the snow particle diameter, mass flow and snow transport rate [1]. In order to analyze snow depth monitor needs, Wang Zhibin proposed setting scheme of snow depth monitoring points and Haerbin-Dalian HighSpeed Railway snow depth system construction program [2].

Table 1. The snow hazard analysis.

\begin{tabular}{|c|c|}
\hline No. & Hazard \\
\hline 1 & $\begin{array}{l}\text { Too much snow can cause slippery track surface on the railway } \\
\text { tracks, leading to decreased braking performance. }\end{array}$ \\
\hline 2 & $\begin{array}{l}\text { Railway tracks cannot be converted flexibly by snow, resulting } \\
\text { in trains cannot run normally. }\end{array}$ \\
\hline 3 & $\begin{array}{l}\text { There is a snowstorm or in early spring may cause visual range } \\
\text { when an avalanche barriers, but also bury the track and turnouts, } \\
\text { leading to the bad result which the train stops, causing train } \\
\text { delays. It can cause serious train derailment and subversion, or } \\
\text { buildings damaged tunnel cracks. }\end{array}$ \\
\hline 4 & $\begin{array}{l}\text { In electrified railway section, parking over time, due to the } \\
\text { snow quality increase, pantograph and catenaries will fall off, } \\
\text { which automatically cut off power supply. }\end{array}$ \\
\hline 5 & $\begin{array}{l}\text { Wet snow can cause snow removal difficulty. Vegetation is } \\
\text { crushed.Wind blowing snow may cause malfunction turnout, } \\
\text { snow removal difficulty adhesion snow will pressure } \\
\text { off the traction power supply and signal wires so making } \\
\text { pantograph fall. }\end{array}$ \\
\hline
\end{tabular}


The system combines laser sensors and video images to measure snow depth. The laser distance sensors get snow depth. Video shot by the image sensor can get track condition to determine whether the track is covered with snow. Snow depth also can be got by capturing the ruler. Meanwhile, the video also provides monitoring device operation to expel the animal or human disturbance and an invalid measurement monitoring caused by storm.

\section{THE OVERALL SCHEME OF RAILWAY DISAS- TER PREVENTION SYSTEM DESIGN MEASURING SNOW}

\subsection{The Overall Design of the System}

System consists of snow depth monitoring point devices and monitoring management center two parts. Snow depth monitoring point devices, including laser and video sensor, control unit, wireless modules, power supplies and other external devices, are capable of real-time acquisition snow depth data of the monitoring stations and snow scene pictures and videos. Real-time monitoring and management center is responsible for receiving data. If it is found in a monitoring site data exceeds a set threshold, the system will alarm. Meanwhile, the system will capture photos and record snowfall live video. Program generates the appropriate decisions according to different alarm levels, so as to achieve the purpose of early warning for disaster prevention [3].

System hardware can achieve acquisition and transmission capabilities, laser and video software system can complete the data analysis, early warning report and the terminal display function.

\subsection{Functional Principle of the System}

The functional principle of the system is shown in Fig. (1).

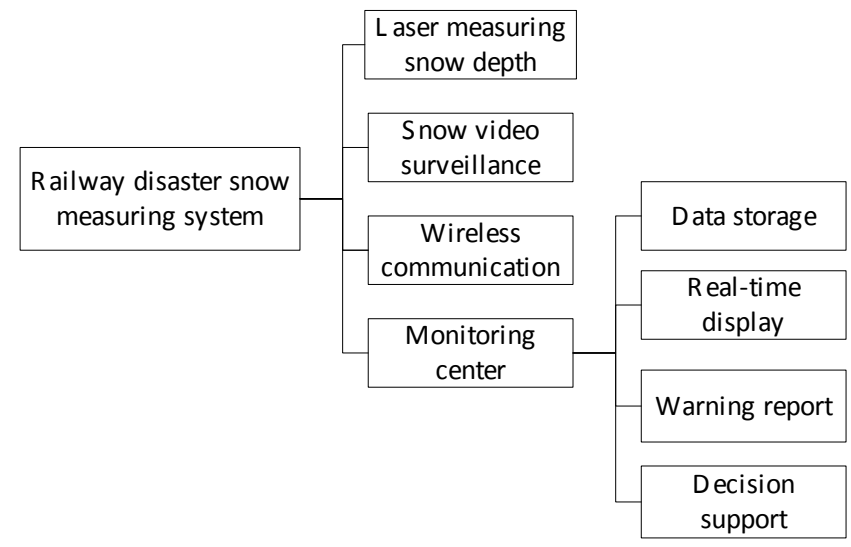

Fig. (1). Structure of railway disaster snow measuring system.

\subsubsection{Snow Depth Laser Distance Sensor Measuring Prin- ciple}

Snow depth is measured by a laser ranging sensor perpendicular to the ground.

The vertical distance is measured directly in general situations or limited to the location principle. This method, however, needs the installation of a rangefinder above the snow surface, which may block the surface and the melt snow on which may fall to the surface, interfering with the measurement.

In comparison, the application of a laser ranging sensor can be of many advantages. A laser beam can be extremely slim with high receiving sensitivity and precision, eliminating the barrier effect and preventing the strong reflection of laser by the snow surface if installed inclined. Another benefit is that it can be installed directly mounted on the column without a cross arm. The range of vertical tilt angle $\alpha$ is usually limited to between $10^{\circ} \sim 45^{\circ}$ [4].

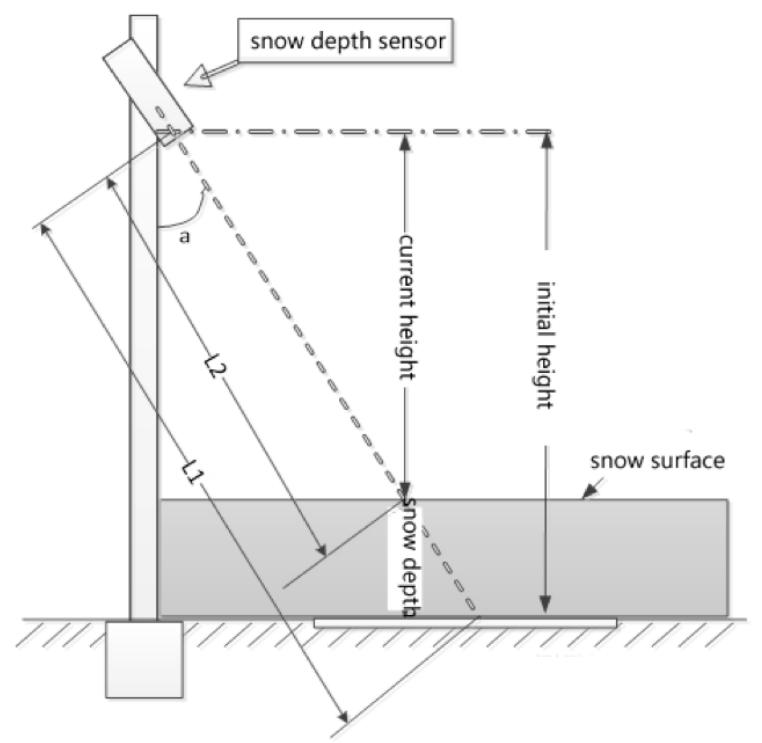

Fig. (2). Laser measuring snow depth diagram.

Fig. (2) is the schematic about principle applied in laser ranging snow depth measurements. Snow depth is the vertical distance $h 1$ between the snow sensor probe and the datum plane minus the vertical distance $h 2$ between the snow sensor probe and the snow surface, namely $h 1$ minus $h 2$ is $h s$.When the sensor is tilt, snow depth ranging unit cannot directly measure the vertical distance $h 1$ and $h 2$. So it can measure the line $L 1$ between the probe and the plane, and the distance $L 2$ between the probe and snow surface.

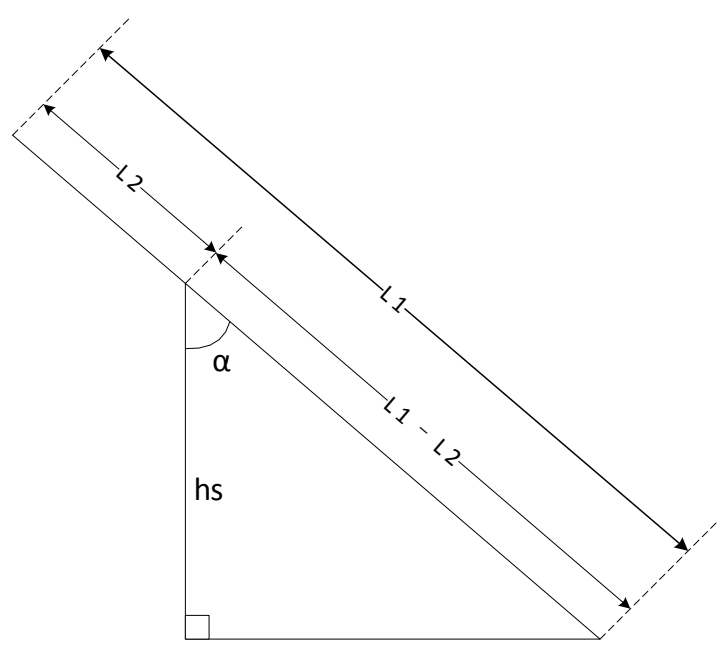

Fig. (3). Snow depth angle converter diagram. 
As shown in Fig. (3) by the triangular relationship transformation, the snow depth can be calculated by the equation (1):

$$
h s=(L 1-L 2) \cos \alpha
$$

Which, $h s$ is the value of snow depth and the unit is meter. $L 1$ is a straight line distance from the probe to the reference plane and the unit is $\mathrm{m} . L 2$ is a straight line distance from the probe to the snow surface and the unit is rad. If the standard height is determined, $L 1$ and $L 2$ can be measured. Equation(1) can inverse transform to equation (2).

$$
a=\cos ^{-1} h s(L 1-L 2)
$$

Which, $h s$ is the height of the standard height block and the unit is $\mathrm{m}$. $L 1$ is a straight line distance from the probe to the reference plane and the unit is $\mathrm{m} . L 2$ is a straight line distance from the probe to the snow surface and the unit is $\mathrm{m}$. Angle $\alpha$ is the diameter vertical angle.

\subsubsection{The Principle of the Video Image Monitoring}

\section{1) Snow detection}

The first purpose of the video surveillance is to detect whether it snows. Once the laser sensor measures the snow, the system alarms. Then the track status is captured to determine whether the track was covered with snow, and if not the alarm should be immediately canceled [5].

2) Snow depth measurements

The scale hot by video camera identifies the depth of the snow, shown in Fig. (4).

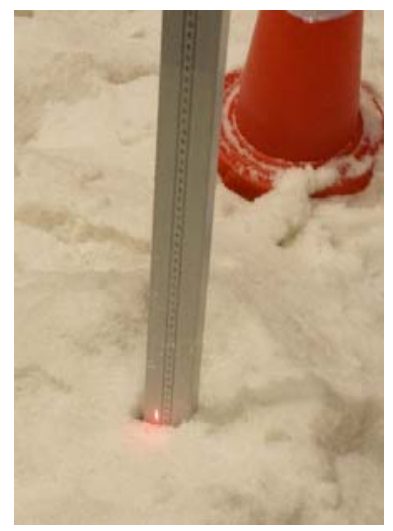

Fig. (4). Scale captured by camera.

This figure is the actual scene of a ski resort, based on the detection point live video image acquisition, snow depth obtained by photographing [6].

3) Video miscellaneous function

The video systems also are designed to have some other auxiliary functions. Cameras shoot laser sensor detection point in order to determine the operation of the sensor device and feedback to the security monitoring station. Referring to the scene captured by camera, damage caused by on-site wind, animal or unusual circumstances vandalism near the railway monitoring point can be watched. After data processing, the relevant commands sent to the relevant service scheduling desk are used to make real-time scheduling [7].

\section{PC SOFTWARE DESIGN}

This system is to deal with the snow disaster prevention. On the basis of data collected by the hardware, PC software mainly achieve storage of data, real-time display, data analysis and other functions.

The Kingview software is used to develop. The configuration software is the area in recent years the rise of industrial automation software development of a new technology with the development of simple short development cycles high universality high reliability [8].

\subsection{The Software Main Interface}

As a key equipment of railway disaster prevention systems, measuring devices can provide the necessary security for railway operation in the heavy snow disaster area. Snow disaster prevention test system in the main interface of the system software is the most direct reflection of the snow conditions, providing basic information for high-speed rail running.

The main interface design as shown in Fig. (5), mainly includes the monitoring site of geographic information, basic information and display alarm function, which shows that alarm is based on real-time snow depth of the data shall be carried out in accordance with the different level alarm display, have confirmed alarm at the same time, the function of the current image and video information to be obtained [9]. The basis of hierarchical alarm shown in the Table 2 .

\subsection{Real-time Monitoring}

Real-time monitoring interface is a real-time acquisition of laser and the video information integration interface. It can get real time snow depth data and video information, according to the need for capturing and video functions. The yellow frame shows the real-time snow depth curve, and the right figure is the real-time numerical and snow depth under the snow depth value corresponding to the speed limit value. Interface is shown in Fig. (6).

\subsection{Historical Data}

Historical data is mainly used for outdoor equipment reading data in memory card from the front, and the relevant statistical analysis, including data entry, data statistic and report forms printing.

\subsection{Data Analysis}

Data analysis is the important function of snow disaster prevention test system software. Its main job is to analyze the data that is acquired by the snow depth monitoring equipment. It can use the data mining technology to forecast and apply the snow depth data [10].

Equipment state is one of the key factors of system reliability. System through this function module can monitor snow depth acquisition equipment and configuration, the laser snow depth, video equipment, wireless communication module monitor the working status of equipment, improving the reliability of the system. 
Table 2. First train speed limit alarm threshold reference value.

\begin{tabular}{|c|c|c|c|c|c|}
\hline Snow depth $L(\mathbf{c m})$ & Speed limit & Alarm mode & Whether or not video & Hazard rating & Warning level \\
\hline $\mathbf{L}<9$ & Not limit & Green light & Don't video & $\mathrm{F}$ & No warning \\
\hline $\mathbf{9}<\mathrm{L}<17$ & $<245 \mathrm{~km} / \mathrm{h}$ & Green flash $(1 \mathrm{~Hz})$ & $\begin{array}{l}\text { Open the video to } 8.5 \\
\mathrm{~cm}(2 \mathrm{~min} / 30 \mathrm{~min})\end{array}$ & $\mathrm{E}$ & Blue warning \\
\hline $17<L<19$ & $<210 \mathrm{~km} / \mathrm{h}$ & Yellow light & $\begin{array}{l}\text { Open the video to } 16.5 \\
\mathrm{~cm}(2 \mathrm{~min} / 30 \mathrm{~min})\end{array}$ & $\mathrm{D}$ & Yellow warning \\
\hline $19<\mathrm{L}<22$ & $<160 \mathrm{~km} / \mathrm{h}$ & Yellow flash $(2 \mathrm{~Hz})$ & $\begin{array}{l}\text { Open the video to } 18.5 \\
\mathrm{~cm}(2 \mathrm{~min} / 30 \mathrm{~min})\end{array}$ & $\mathrm{C}$ & Orange warning \\
\hline $22<\mathrm{L}<30$ & $<110 \mathrm{~km} / \mathrm{h}$ & Red light & $\begin{array}{l}\text { Open the video to } 21.5 \\
\mathrm{~cm}(2 \mathrm{~min} / 30 \mathrm{~min})\end{array}$ & B & Red warning \\
\hline $\mathbf{L}>\mathbf{3 0}$ & Artificial control & Red flash $(4 \mathrm{~Hz})$ & $\begin{array}{l}\text { Open the video to } 29.5 \\
\mathrm{~cm}(2 \mathrm{~min} / 30 \mathrm{~min})\end{array}$ & A & Red warning \\
\hline
\end{tabular}

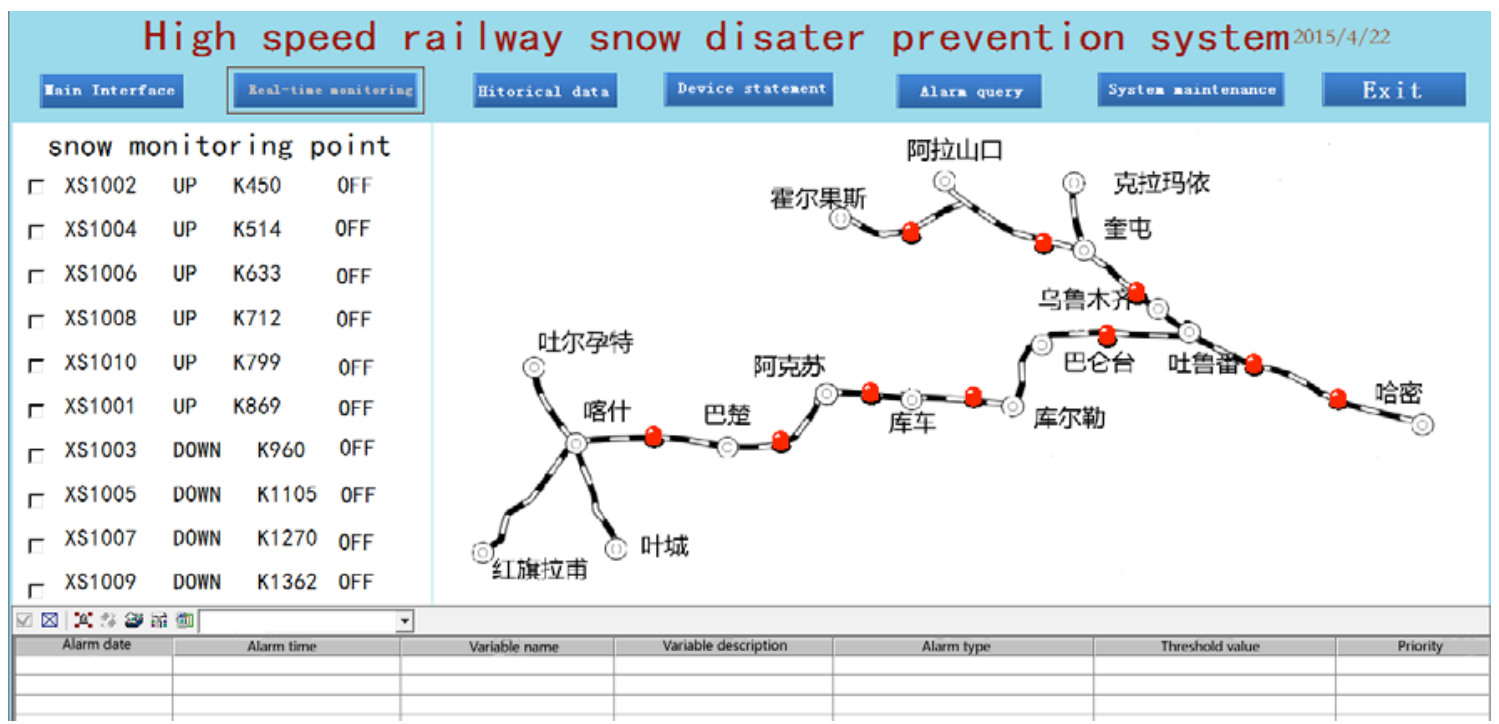

Fig. (5). The main interface.

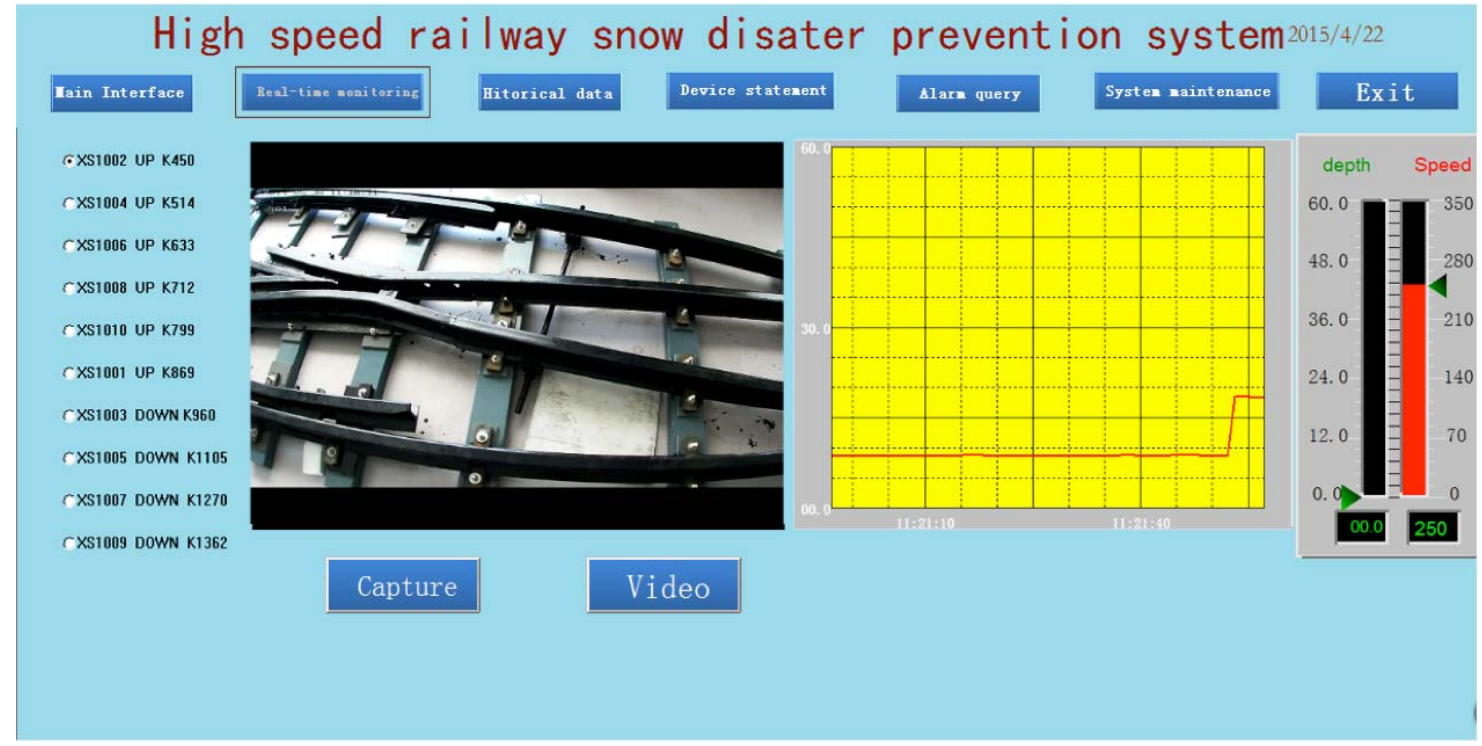

Fig. (6). Real-time monitoring interface sketch. 


\subsection{Network Communication Configuration}

It includes wired and wireless network communication in two ways, corresponding to different connection conditions. Cable configuration: RJ45 Ethernet and serial port 232. Wireless configuration: network IP configuration.

\subsection{User Management}

Login system is mainly used for the user to enter data management system for security check, preventing strangers to enter the system, database malicious tampering or damage. At the same time, the system will set different users permissions to operate.

\subsection{Other Features}

System will also design memo function, let the staff record the idea.

\section{SNOW DISASTER PREVENTION SYSTEM TEST- ING}

After the system is completed, it needs on-site debugging and actual test. The operation process of the whole system is shown below. First the laser ranging sensor measures snow depth and the video system shoots. Snow depth data, videos and photos are sent to the monitoring center. If the snow depth reaches a certain limit, the system will alarm. Through the video staff can determine whether the alarm is false. If it is a false alarm, the alarm should be canceled. If it is real, then a dispatching command should be done [11].

\subsection{System Function Test}

Under the condition of laboratory, experiment is operated on the cable connection. Video equipment is installed on the portable tripod. The test object is railway platform. As shown in Fig. (7) and Fig. (8).

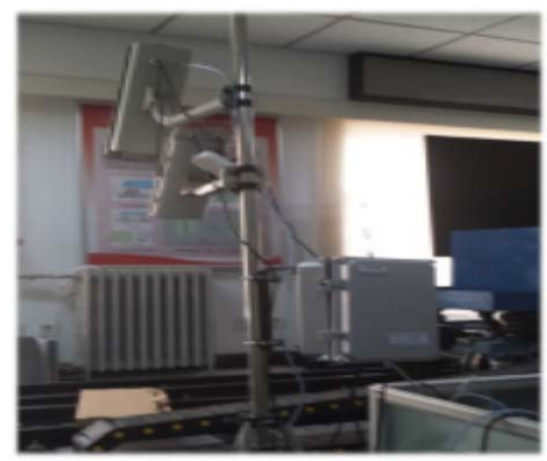

Fig. (7). Snow measuring device.

Snow comparison between test and simulation of snow thickness under different shades verifies accuracy and makes the right response. Based on the system setting, the frequency of the real-time acquisition of data is a third HZ. Every minute in the database records a snow depth value [12].

Test plan is shown below. First material A will be put on the railway platform. The thickness of A is instead of snow depth. Snow depth value is $9 \mathrm{~cm}$ so that the speed of train is not limited [13].

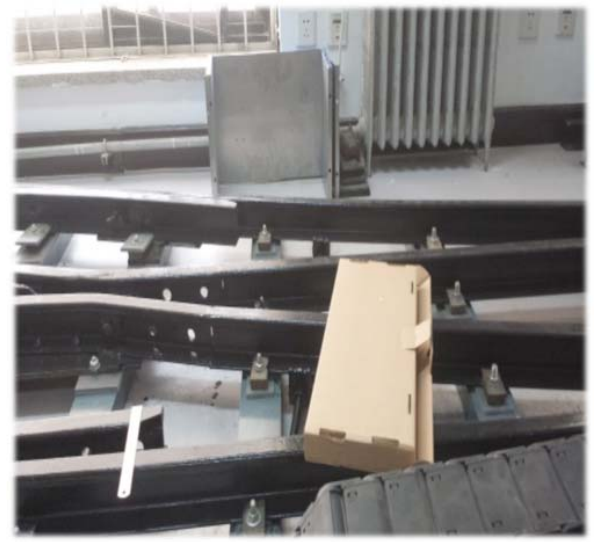

Fig. (8). Railway platform.

Then material B will be put on the material A. From figure in real-time monitoring, when $\mathrm{B}$ into $\mathrm{A}$ top, the curve changes, snow depth value of $18 \mathrm{~cm}$, numerical and speed information, the most the right side shows values of speed limit of $210 \mathrm{~km} / \mathrm{h}$, for railway train speed to make A reference. As shown in Fig. (9).

Can be seen in the figure, the snow depth value is $18 \mathrm{~cm}$ and the alarm level is yellow warning. It is obvious that the red curve has a mutation in a yellow table.

\subsection{System Test in Ski Resort}

In order to simulate the actual snow scene, QiaoBo ski resort is selected as a test place.

The experiments will be performed to simulate last snowing and foreign interference.

Scene 1 is the process of snowing.

Artificial method is used to simulate the actual snow. Then one test measured data is shown in Fig. (10).

Can be seen from Fig. (10) laser measurement and artificial measurement results are roughly the same. Meanwhile it also illustrates the system measurement is accurate. Laser measurement and artificial measurement of correlation coefficient is 0.995 , and also shows the accuracy of the laser ranging.

Scene 2 is foreign interference.

To illustrate how to remove the interference of foreign matter, the following algorithm is proposed.

First the relevant knowledge of meteorology provides the practical basis for the proposed algorithm. In meteorology, snowfall was a standard container will be collected $12 \mathrm{~h}$ or $24 \mathrm{~h}$ after snow into water, measured values, the unit for $\mathrm{mm}$.

Light snow refers to the snow when the horizontal visibility distance equal to or greater than 1000 meters snow depth is below $3 \mathrm{~cm}$ and snow precipitation grades for 24 hours between $0.1 \sim 2.4 \mathrm{~mm}$.

Moderate snow refers to the snow when the horizontal visibility distance between $500 \sim 1000$ meters snow depth is between 3 and $5 \mathrm{~cm}$ and 24 hours of snow up to $2.5 \sim 4.9$ $\mathrm{mm}$. 


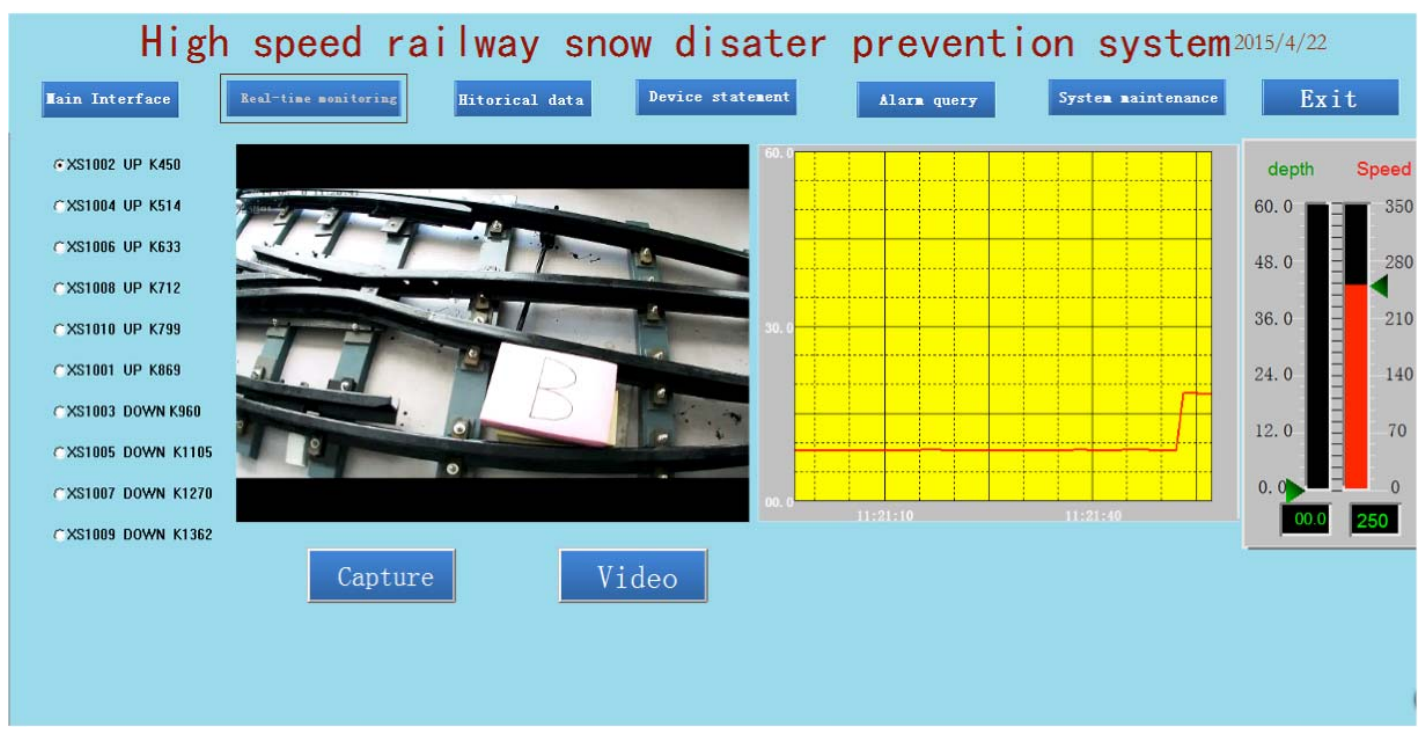

Fig. (9). Real-time monitoring when put B on the A.

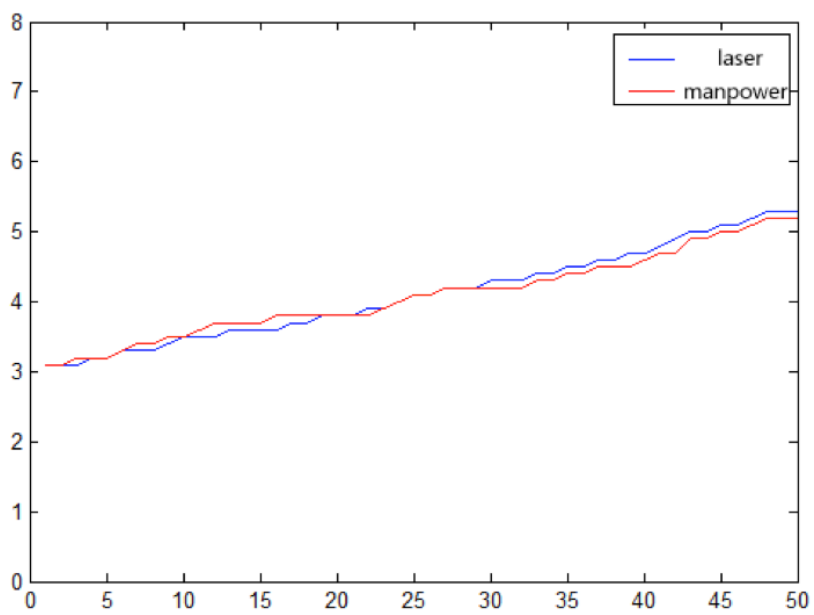

Fig. (10). Experimental data of scene 1 .

Huge snow refers to the snow when visibility is very poor even the level of visibility distance is less than 500 meters the ground snow depth is equal to or greater than $5 \mathrm{~cm}$.

Blizzard refers to the snowfall for 24 hours is $10.0 \sim 19.9$ $\mathrm{mm}$ [14];

Great blizzard refers to the snowfall for 24 hours is 20.0 $\sim 29.9 \mathrm{~mm}$;

Super-large blizzard refers to the snowfall for 24 hours is more than $30.0 \mathrm{~mm}$

From the above data, the thickness of snow accumulation is very slow. Especially for a minute of snow thickness variation, thickness variation is very slow. When foreign body disturbs, the slope of the snow thickness change amplitude will increase. Therefore the thickness of snow per minute change is checked to determine if there was any foreign interference.

The equation as followed can be used to describe it.

$k=\frac{h(n)-h(n-1)}{t_{n}-t_{n-1}}$
Among them, $h(n)$ is the thickness of snow of the moment and value $k$ is the snow thickness change slope.

When $|k| \geq\left|k_{\text {set }}\right|$ surpasses a certain range, there exists foreign interference. The value $|k|$ can be fixed according to the situation of the snow, such as under a light snow, moderate snow, blizzard, and big blizzard or snowmelt down; when the situation is different the value will be divergent.

In the above method, typically the value $\left|k_{\text {set }}\right|$ is preset. The change of snow depth would be predicted if the system stored the prior knowledge.

The different weather circumstances results in different values. To avoid this kind of trouble, the following algorithm is adopted to improve.

$$
k_{\text {rat }} \%=\frac{k_{n}-\operatorname{average}\left(\sum_{j=n-i}^{n-1} k_{j}\right)}{\operatorname{average}\left(\sum_{j=n-i}^{n-1} k_{j}\right)} \times 100 \%
$$


Among them, average $\left(\sum_{j=n-i}^{n-1} k_{j}\right)$ refers to an average value of $\sum_{j=n-i}^{n-1} k_{j}$ (the value cannot be zero).

When $\left|k_{\text {rat }} \%\right|>200 \%$ (or can be set according to the actual situation), it can be judged the foreign interference occurs.

In order to describe explicitly, the simulation software Matlab is used to simulate the foreign body disturbance. As shown in Fig. (11) and Fig. (12).

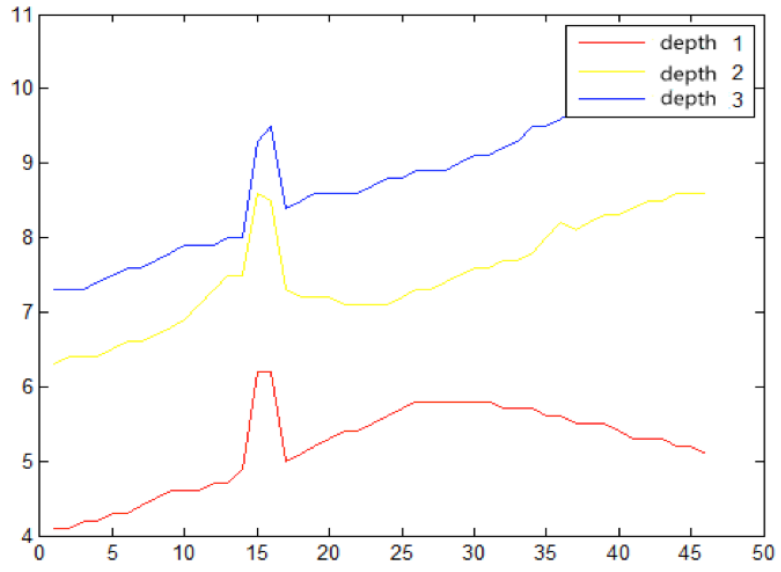

Fig. (11). Snow depth change curve.

The Fig. (11) shows the simulation, to add foreign interference, when time 15.The rate of change of snow depth achieves maximum at the moment 15 and $\left|k_{\text {rat }} \%\right|>500 \%$ is satisfied. So it can be judged that foreign interference is indeed happed at that time.

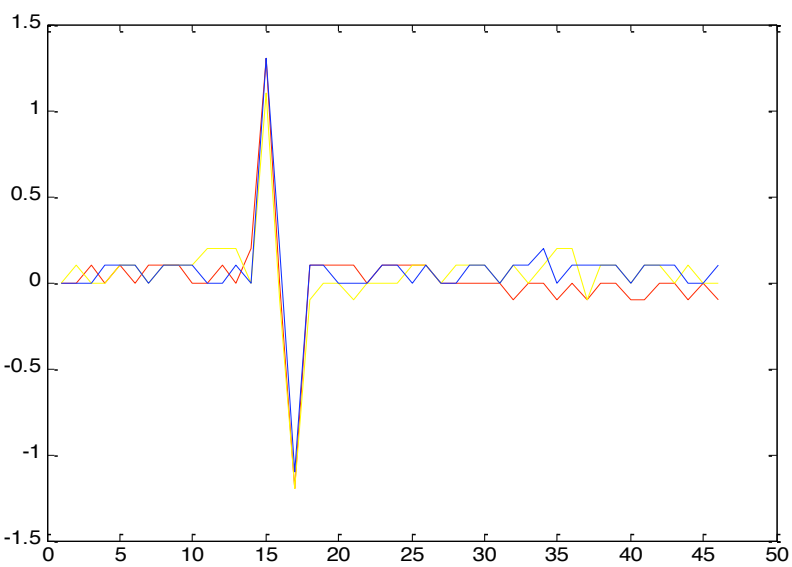

Fig. (12). Snow depth change curve of the slope.

\subsection{Result Analysis}

After the above tests about the snow measurements, the system is feasible to achieve the purpose of measuring the snow from the perspective of data accuracy. The systems can real-time access to snow depth data and record history data at a certain time interval. In the actual test the system is also proved to adapt to environmental requirements. Foreign material processing algorithm proposed is feasible after the actual verification. Of course the system needs to be further optimized and improved.

\section{CONCLUSION}

The system designed in this paper can realize real-time online monitoring of snow on railway, measuring current snow depth during snowing. The video-assisted system can play a supporting role when the laser equipment does not work. Also the snowfall conditions can be observed according to the snow photograph taken by monitoring system.

The system designed in this paper is based on multi sensor information fusion of laser and video, providing two kinds of criterion like data and images which can increase the reliability and practicability. The final purpose of this design is to increase the security of railway.

In future research, according to the forecast of the meteorological departments and combining with the current thickness of snow and snowfall, the design can predict the short term snowpack and intensity of snowfall within the next short time ( $1 \mathrm{~h}$ or $2 \mathrm{~h}$ ). After several years of data accumulation, data mining technology and gray model or Markov model can be used to obtain the snow condition prediction model of the monitoring areas. This potential model takes historical data, current weather forecasts and other auxiliary data available as parameters input to predict parameters of snowfall in the monitoring areas.

\section{CONFLICT OF INTEREST}

The authors confirm that this article content has no conflict of interest.

\section{ACKNOWLEDGEMENTS}

This work was financially supported by key techniques in the high speed train operation organization scheme optimization design (2009BAG12A10) and china railway corporation research and development of science and technology plan project (2014T002-A).

\section{REFERENCES}

[1] T. Sato, T. Uematsu, T. Nakata, and Y. Kaneda, "Three dimensional numerical simulation of snowdrift," Journal of Wind Engineering and Industrial Aerodynamics, vol. 46-47, pp. 741-746, 1993.

[2] S. Thordarson, and H. Norem, "Simulation of two-dimensiona wind flow and snowdrifting application for roads: part I[C]," Snow Engineering, Hjonh-Hansen, Holant, Laset \& Noreln, 2000 Rottardam.

[3] J.H.M. Beyers, P.A. Sundsbo, and T.M. Harms, "Numerical simulation of three dimensional transient Snow drifting around a cube," Journal of Wind Engineering and Industrial Aerodynamics, vol. 92, pp. 725-747, 2004

[4] P.A. Sundsbo, "Numerical simulations of wind deflection fins to control snowaccumulation inbuilding steps," Journal of Wind Engineering and Industrial Aerodynamics, vol. 74-76, pp. 543-552, 1998.

[5] R.D. Tabler, "Design Guidelines for the Control of Blowing and Drifting Snow," Strategic Highway Research Program (SHRP-H381) National Council Washington, DC, 1994.

[6] K. Sugiura, K. Nishimura, N. Maeno, and T. Kimura "Measurements of snow mass flux and transport rate at different particle di- 
ameters in drifting snow," Cold Regions Science and Technology, vol. 27, no. 2, pp. 83-89, 1998.

[7] E.M. Greene, G.E. Liston, and R.A. Pielke Sr. "Simulation of above tree line snowdrift formation using a numerical snowtransport model," Cold Regions Science and Technology, vol. 30, no. 1-3, pp. 135-144, 1999.

[8] R.D. Tabler, "Controlling and Blowing and Drifting Snow with Snow Fences and Road Design," Niwot, Colorado, America: Tibler and Associates, 2003.

[9] K. Kosugi, T. Sato, and A. Sato, "Dependence of drifting snow saltation lengths on snow surface hardness," Cold Regions Science and Technology, vol. 39, no. 2, pp. 133-139, 2004.

[10] J.G. Choi, and P.H. Seong, "Software dependability models under memory faults with application to adigital system in nuclear power plants," Reliability Engineering \& System Safety, vol. 59, no. 3, pp. 321-329, 1998.
[11] K. Kanolln, and M. Ortalo-Borrel, "Fault-tolerant system dependability-explicit modeling of hardwareand soft-ware componentinteractions," IEEE Transactions on Reliability, vol. 49, no. 4, pp. 363-376, 2000.

[12] J.T. Pulliainen, J. Grandell, and M.T. Hallikainen, "HUT snow emission model and its applicability to snow water equivalent retrieval," Geosciences and Remote Sensing, IEEE Transactions on, vol. 37, no. 3, pp. 1378-1390, 1999.

[13] Z.B. Wang, "Approach to snow depth detecting system on haerbindalian passenger dedicated line," Railway Standard Design, vol. 5, pp. 165-168, 2012.

[14] N. Wang, "Disaster prevention and safe monitoring system for high speed railway," Railway Computer Application, vol. 21, no. 7, pp. 56-56, 2012.

Received: May 26, 2015

Revised: July 14, 2015

Accepted: August 10, 2015

(C) Qin et al.; Licensee Bentham Open.

This is an open access article licensed under the terms of the (https://creativecommons.org/licenses/by/4.0/legalcode), which permits unrestricted, noncommercial use, distribution and reproduction in any medium, provided the work is properly cited. 